\title{
The Education for Sustainability Jig-Saw Puzzle: Implementation in Universities
}

\author{
Ian Thomas ${ }^{1}$, Kathryn Hegarty ${ }^{1}$, Sarah Holdsworth ${ }^{2}$ \\ ${ }^{1}$ School of Global, Urban and Social Studies, RMIT University, Melbourne, Australia \\ ${ }^{2}$ School of Property Construction and Project Management, RMIT University, Melbourne, Australia \\ Email: Ian.thomas@rmit.edu.au
}

Received July $3^{\text {rd }}$, 2012; revised August $4^{\text {th }}$, 2012; accepted August $16^{\text {th }}, 2012$

\begin{abstract}
Why is it taking so long to implement curriculum change for Education for Sustainability (EfS)? Despite a wealth of literature and government reporting about the need for EfS, we have seen few moves to include EfS across the curriculum in universities. Importantly, the sort of curriculum change we are seeking represents a complex process in complex organizations. No single factor affects this type of change. Rather there are several interconnecting aspects of organizations, disciplines, individuals, and beliefs. Hence, in discussing curriculum change we identify the roles of: organizational change; institutional strategies; academic development; curriculum development; learning and teaching practice; pedagogy; the campus; graduate attributes; and professional associations. Overall we do not offer a quick solution, rather we identify the need for a systemic approach to recognizing the range of elements that make up the EfS picture, and how they relate to one another. In parallel we recognize the role that the values of disciplines, and the academics themselves, play in influencing all the elements we have discussed. Our proposition is that if we all recognize the issues discussed, and tailor our responses to the situations of the university (and disciplines) we have targeted, then we can facilitate implementation of EfS.
\end{abstract}

Keywords: Sustainable Development; Sustainability Education; Universities; Implementation

\section{Introduction}

Why is it taking so long to implement education for sustainability (EFS) in university Curricular? Although there has been debate about the direction and substance of EfS, the need for EfS to be the underlying element of university education has been widely recognized (e.g. Holdsworth et al., 2006a, 2006b \& 2009; Sterling \& Thomas, 2006). Government policy documents confirm this need, e.g. Department of the Environment, Water, Heritage and the Arts (2009) and Higher Education Funding Council for England (2009) and the recent promotion of "green jobs", such as the Victorian Action Plan for Green Jobs (Department of Innovation, Industry and Regional Development, 2010) further accentuates the need for education and training in sustainability fields.

There have been responses from academics involved in the development of EfS based subjects (e.g. Sherren, 2007) and resources developed to assist curriculum development (e.g. University Leaders for a Sustainable Future, 2006; Association for the Advancement of Sustainability in Higher Education, 2010). Given all this interest we could expect a much greater adoption of EfS and should have seen its incorporation into university curricula. Yet overviews of activity (e.g. Tilbury et al., 2005; Lang et al., 2006), indicate that there has been little attempt to introduce sustainability into the curriculum, other than through isolated subjects that are often electives.

So what is inhibiting this adoption? Among others, Dawe et al. (2005), Filho (2000), Hegarty (2008) and Thomas (2004) identify several key inhibitors; a lack of understanding and training for academics; contested nature of sustainability; already crowded curriculum; time and resources required for staff to developed knowledge and skills; lack of institutional drivers; disciplinary cultures and assumptions. The implication is that there is no one inhibitor to EfS, and no clear action that will remove the inhibitors and bring about the implementation at a university. Rather we see that there is a number of elements that need to fit together, as a jig-saw puzzle does, to help us complete the EfS picture at a given university. Consequently, in this paper we have created the equivalent of a jig-saw to help change agents work on implementation of EfS. We discuss the key elements of the jig-saw puzzle that need to be considered when we are looking to implement EfS, which include; organizational change, academic development; the sustainability educational praxis (encompassing the internal drivers of graduate attributes, and the related role of industry and professional associations).

The plan to implement $\mathrm{EfS}^{1}$ at a particular university will need to consider these elements, but their mix will be unique to each institution. We offer no one solution for implementing EfS; it would be naive to think that may be possible given the complex mix of university structures and academics. The challenge for all of us involved in EfS in universities is to understand how each element relates to our own institution, and then how we can use this understanding to drive the implementation of EfS. Meeting this challenge will require creativity; to interpret the issues and experiences we discuss, and to adapt them to specific situations.

\footnotetext{
Throughout this paper we will focus on the development of Education for Sustainability, however we acknowledge the debate around the terminology and associated meanings of sustainability education and Education for Sustainable Development (Sterling \& Thomas, 2006). While we recognise the important philosophical differences which affect choices of terminology issues raised here are relevant to curriculum change for sustainability, whatever terminology used.
} 
Creativity is defined by Robinson (2001: p. 118) as "imaginative processes with outcomes that are original and of value”. In this context, utilizing the elements discussed here to implement EfS achieves an outcome that will be unique to a particular institution, and of value to the goals of sustainability and to the academics involved, though the learning they too will achieve.

\section{Organizational Change and Development of Institutional Strategies}

Universities are complex work-based organizations. They have a history going back over several centuries (Ford, 2002), however, the Twentieth Century saw a growth in the number of universities and their size (e.g. RMIT in Australia had over 74,000 students in 2012-RMIT, 2012). To manage such organizations we have management or organizational structures, and documents to guide the management (i.e. policies and procedures). Yet it is the people, especially academics, who play a pivotal role.

De la Harpe and Thomas (2009) have touched on the many aspects of institutional change that affect EfS. They note that the literature on curriculum change in higher education indicates that there is a number of factors that are critical for success. For example, for successful change to occur Eckel et al. (1999) considered essential elements to be: understanding the change process; understanding why change is needed; and implementing change.

Coupled with these broad issues, Lang et al. (2006) noted that there is a range of issues that have been identified as necessary supports for the development of EFS, including creation of sustainability plans for the university and curriculum, and support of the executive board. However, the results of a survey of Australian universities in the mid-2000s indicated (Lang et al., 2006: p. 55) that there did “... not appear that specific, coordinated and systemic strategies for EfS have been developed by any Australian university. This may be a contributing reason as to why there is little EfS activity within the universities.”

There is a clear link between curriculum change and organizational change: they both require adequate investment in time and commitment across all levels of the organization. The literature associated with organizational change in universities (e.g. Eckel, 2002; McGinty \& McTaggart, 2000) indicates the complexities. Achieving change in teaching practice and the curriculum will require an understanding of the change process, both internal influences for change (including beliefs and concepts of teaching) and external influences for change (workplace dimensions and culture). Without this understanding, curriculum change programs are unlikely to create lasting change for sustainability.

\section{Academic Development}

Educators play a key role in presenting the understanding associated with sustainability and developing it in their students. Specifically, academic development is necessary to provide educators with the capacity for understanding sustainability as an overarching conceptual framework (Huckle, 2005). Further, Tilbury et al. (2005) point out that academic development is also an important step in providing educators with the capacity to undertake sustainability educational praxis.

For successful academic development the distinctive dominant culture of a university must be understood and built into its pedagogy, learning and teaching approaches and curriculum. University culture is shaped internally by the notion of academic freedom and autonomy; externally the university structure, and its values and beliefs lead to the development of a distinctive academic culture (Hegarty, 2008) The ability of a university and the individual to adapt to these is determined by its culture and the influence of the faculty, the administration, the discipline and the whole organization. Hegarty (2008) argues that academic and disciplinary modes of identity, the constituent elements of scholarly culture, inform and shape practice. It is essential to understand university culture to minimize conflict and to foster the development of shared goals that may result from any academic development program. However, a review of actions to operationalize sustainability education specifically through professional development programs within higher educational institutions by Holdsworth et al. (2008) found that there are limited opportunities for academics to engage with the concept of sustainability and little support for curriculum development.

Academic development for sustainability education should enable educators to develop sustainability education praxis. This includes the development of pedagogical knowledge (Kolb, 1967; Rowland, 2003), instructional knowledge (Kreber, 1999) and curricular knowledge (Gibbs, 1995; Trigwell, 1995). These elements should be interlinked to form a central framework for exploring sustainability across the area of the scholarship of learning and teaching, as it relates to the unique culture and structure of universities (Kreber, 1999). This approach must be grounded in a learner-centred pedagogy, as the learner must develop skills in critical practice, reflective practice and systemic thinking (Kemmis \& Smith, 2008).

In addition, academic development programs must link the improvement of the scholarship of teaching and learning with the scholarship of research; only then will the role of academic development be fully valued (Boyer, 1990). Further, academic development programs need to be initially focused within the discipline (Hegarty, 2008), disciplinary assumptions must be understood and explained (Barnett, 1997; Rowland, 2003). Academic development is best received from developers within the discipline itself, as tension may exist between academic developers who sit outside of the area of change and are not perceived as experts in the discipline (Rowland, 2003). As elaborated by Sterling and Thomas (2006) “... it will be difficult for academics who have not been studying EfS to do all the work to develop a set of capabilities themselves, not least as it engages them in a role as learners as teachers (p. 363)."

This discussion shows that development programs must entail much more than providing academics with materials about topics or how to teach; rather programs that engage the academics in active learning are indicated.

\section{Sustainability Education: Curriculum; Learning and Teaching Practice; and Pedagogy}

The term "curriculum" means "the aggregate of courses of study given in a school, college or university" (Macquarie University, 1981). This "aggregate" is comprised of the formal learning experiences provided to students, and which in turn is the sum of the knowledge (or subject content) that is conveyed, plus the understanding that is generated through the pedagogy (or process) that is used. Both content and pedagogy are important, but as we will discuss, for EfS pedagogy is particularly 
important.

When we look at the activities of many academics we see an interest in being involved with sustainability (e.g. Thomas \& Nicitia, 2002), however, the concepts of sustainability are contested (Cotton et al., 2007; Filho, 2000). In relation to Plymouth University in the UK, Jones et al. (2009) explored the perceptions of academics and students towards embedding education for sustainable development (ESD) into undergraduate degree programs. The study identified that there was uncertainty about the meaning and application of the term ESD. Further, there was a widely held view that the term ESD was related to content rather than pedagogy.

The Plymouth study emphasizes the point of "embedding" sustainability in the curricula of university programs. Such is the purpose of EfS. As Sterling and Thomas (2006) have discussed the options for incorporating sustainability at universities and argued that every subject/course/module that a student will take should add to the student's sustainability education. As an illustration, Holdsworth et al. (2006a) described an approach to deal with the concern of 'curriculum overload' by working with academics to review their curricula to accentuate elements of sustainability in their teaching rather than adding additional material.

At this point it is important to recognize the discussions associated with pedagogical approaches for EfS. In particular Cotton et al. (2007) and Corneya and Reid (2007) argue that education about sustainable development simply transmits "factual" information about sustainability concepts and processes (leaving existing assumptions unchallenged) using didactic educational approaches, while education in sustainable development uses experiential and interactive learning processes (a more learner-centred approach) to nurture an emotional connection and assist in the development of greater understanding. However, education for sustainable development is oriented towards a more transformative approach to education encouraging the adoption of sustainability principles, ethics and values. Hegarty (2008) reinforces the point, arguing the role that politics, personal, professional and disciplinary practice shape our understanding of education and sustainability. Transformative change will only occur if we recognize and explore these concepts.

Given that the complexities of the sustainability paradigm a new approach to understanding and doing (Marinova \& McGrath, 2004) is required. Fien (2001: p. 24) argues that sustainability education pedagogy must encourage educators to include the exploration of "questions, issues and problems of sustainability, especially in contexts relevant to them and their communities” Specifically, to achieve significant transformative learning, Sterling (2001) argues we need to move beyond a reductionist pedagogy, and adopt pedagogies that are interactive enquiry-based and student-centred (Corneya \& Reid, 2007; Fien, 2001; Tilbury et al., 2005), i.e. those which epitomize constructivist learning. For transformation EfS requires dialogical, critical and active learning (deep learning), which in turn is based on pedagogy in which teachers and students learn, reflect and act together, and by doing so transform themselves and the world around them (Huckle, 2005; Sterling, 2001).

Critically, any lack of understanding of pedagogy and loss of traditional educational praxis (as discussed by Fien, 2001; Kemmis \& Smith, 2008) directly affects the type of curriculum developed. As noted by Fien (2001) educators, unconscious of their own values and norms, may support understand- ing and reinforcement of "the existing social and cultural mores” (p. 23). This legitimates and reinforces the behaviors and lifestyle choices operating in our communities. As a consequence there is no one "correct" conception of sustainable development; neither is there one unique pedagogic approach for EfS. However, the discussion above highlights key principles for EfS, specifically the pedagogy we need to pursue; a pedagogy which must appreciate the role of disciplinary and individual values in academics’ praxis.

\section{The Campus Being a "Learning Laboratory" and Congruent with EfS}

Many universities have engaged positively with environmental management, as typified by Sustainable Campus Group (2009) and increasingly for more than singular economic reasons (e.g. as a recruiting tool; Morris, 2005). This provides opportunities for linking the academic activities of students with the research and practical experiences associated with the environmental management of a university campus (M'Gonigle \& Starke, 2006). Consistently student projects have been encouraged both within the universities (Khaleeli, 2006; Noonan \& Thomas, 2004), and in conjunction with neighboring communities (Lederer \& Seasons, 2005; Savan, 2004).

Recently authors such as Creighton (1998), Beringer (2006) and Wells et al. (2009) have argued that the campus is a learning laboratory for students to engage in activities that complement their formal academic studies. However, projects and research associated with sustainability cannot simply be added to a subject offered to students. The inclusion of a sustainability example, or focus, needs the academics to change their teaching approach as well as the content of the subject (e.g. to include team work), and probably the assessment tasks (Brunetti, Royann \& Sawada, 2003).

\section{Graduate Attributes for Education for Sustainability and Employment}

The learning that students have achieved at the end of their studies should be both evident and related to the purpose of their education. Specifically, what are the objectives of our teaching - what are the leaning outcomes we want from our students? In other words, we (educators) need to articulate the attributes (the term we will mainly use), abilities, capabilities or competences that they should achieve as a result of their EfS.

Approaches to learning and teaching identified within the literature, and reflecting the character of sustainability pedagogies, propose that students become capable in a range attributes (see Figure 1). Importantly, Parkin et al. (2004) argue that students should develop attributes in relation to their likely sphere of influence in the future; in effect work-based or professional skills. Broadly then, the attributes need to cover:

- professional specific knowledge, understanding and skills

- professional transferable knowledge, understanding and skills

- personal transferable knowledge, understanding and skills.

The categories "generic" and "transferable" attributes are also used by Pitman and Broomhall (2009) to cover these areas. Providing this range of attributes is going to be difficult in the limited time-period of a typical education program: as the Higher Education Academy (2006: p. 6) report notes "many of these skills and attributes are not easy to teach in a traditional 
sense". However, a structure for delivering EfS attributes can be to identify a hierarchy of learning where progressively more understanding is expected of students. An example of such a hierarchy for EfS is illustrated in Figure 2.

Encouragingly many of the attributes that have been identified as critical for EfS are being adopted by universities. For example the survey by Pitman and Broomhall (2009) of relevant policy documents of Australian universities indicated a wide range of attributes that were being expected of graduates, over half of which relate directly to the characteristics of sustainability pedagogies (noted above). With these attributes there is room for different interpretations of the terms used, and which characteristic matches with which university attribute. Even so, there is a strong indication that Australian universities are looking for generic attributes that cover many aspects of the

- Development of knowledge from the learning process;

- Questioning of their assumptions;

- Recognition that constructing knowledge involves critical analysis; dialogue and reflection;

- Development in complex reasoning;

- $\quad$ Practice in demonstration of knowledge and skills;

- Practice in transferable problem solving skills;

- Practice in the recognition of values and how this relates to their own action;

- $\quad$ Strategies for change;

- Uncertainty in data, analysis and decision-making;

- Critical analysis the theories, data and values being presented to them;

- Identify the connections between the principles of sustainable development and the disciplinary theory;

- Ability to challenge injustice and inequalities;

- Cooperation and conflict resolution;

- Critical thinking;

- Respect for people and things;

- Ability to understand their own sense of identity and self-esteem;

- Value and respect for diversity.

Figure 1.

Graduate attributes associated with Education for Sustainability (Sources Holdsworth et al., 2006a; Parker, Wade \& Van Wensum, 2004; Parkin et al., 2004).

- $\quad$ Awareness - students need to be aware of sustainable development as a consideration in twenty-first century culture, and of how "environment, society, and economics" feature in their studies.

- Process-building on "awareness", students should be able to recognize that the principles of sustainable development are the starting point to an intervention or action rather than an end product (we cannot definitively describe or draw what we mean by "sustainable development", so the principles provide a direction to move in, rather than a final state).

- Integration-using students' previous experiences and understanding, rather than being seen as an extra, the principles of sustainable development should be integral to best practice in each subject and discipline.

- Transformative - the principles of sustainable development should be intimately linked to student learning within their subjects on three levels: educational; professional and personal; discipline culture and graduate capabilities. This is the deepest manifestation of EfS where, without direction, students operate as critically reflective practitioners of sustainable development.

- Each university, each program and subject teacher would have to develop these stages in the hierarchy to suit their particular needs.

Figure 2 .

Hierarchy of learning for Education for Sustainability (Source Sterling \& Thomas, 2006) professional and personal transferable aspects associated with EfS.

That universities are pursuing these attributes is a good sign, since employers are looking for similar abilities in the graduates they hire. Since the mid-1990s employers have been reasonably clear about the generic skills that they want to see in their employees (Bowden \& Masters, 1993); e.g. literacy, teamwork, problem solving and communication skills. As a consequence Pitman and Broomhall (2009: p. 440) note that university attributes came as the "response to a call from the business community for the post-compulsory education sector to produce graduates with contemporary, assessable and functional skills needed for the immediate and long-term economic benefit of the country."

The emphasis on generic attributes, and those attributes relevant to workplace situations (e.g. broad analytical approaches and problem-solving) are especially evident in the discussion above. Also, we see a strong similarity between the sets of attributes being sought by employers and those now being identified by our universities-and being relevant to EfS.

\section{The Role of Professional Association and/or Other Accrediting Bodies}

Professional associations (PA) have a close relationship with universities and training institutions. It is these institutions that educate the graduates who become the members of the PAs. Currently in Australia, and other countries, there is a growing interest in sustainable development (sometimes 'sustainability'), especially in the context of concerns related to climate change. Occasionally an individual PA has chosen to require its members to practice their profession in accordance with sustainable development principles (e.g. Australian Institute of Management 2008). Likewise, some seek to ensure that entering members have capabilities in sustainable development by virtue of a relevant university degree (e.g. Engineers Australia, 2006). So, while there is considerable potential for PAs to exert influence over the curriculum offered at universities, and act as a driver to introduce EfS, the extent to which this is happening is unclear.

The evolution of PAs has a long history, as indicated by Carr-Saunders and Wilson (1968). According to Babylon Ltd. (2009) "a professional association is an organization, usually non-profit, that exists to further a particular profession, to protect both the public interest and the interests of professionals ..." Specifically, involvement of PAs in the development of competency based approaches to assessing the performance of students (potential members of the PAs) has been noted by Gonczi (1994), who comments on the widespread involvement of Australian PAs in working with governments and universities on this project. An aspect of this involvement was the opportunity for PAs to act as innovators, and in the context of sustainable development Dzinkowski (2007) and Oblinger (2009) report examples of how innovation has been facilitated through PAs.

Hence, PAs may play an important role in shaping the curriculum of university programs - if they choose to do so. However, are PAs using their influence to promote the adoption of EfS curriculum? Results from a desk-top (web-based) survey of PAs in Australia indicated that very few of the PAs have engaged in sustainability and related issues (Thomas et al., 2012). Roughly $6 \%$ of the sample indicated a strong connection to sustainability (i.e. where the three aspects environment, society 
and broad economic understanding were all identifiable). Further, only around one-third had accreditation procedures to influence university programs.

Overall it appears that for most university programs in Australia PAs cannot, currently, be expected to influence the adoption of EfS. However, the results did indicate the potential influence that PAs could exert, to become another factor in the range of drivers for EfS.

\section{Is There a Role for Ockham's Razor'?}

From the foregoing what can we conclude? On the surface we see that there is no simple approach to implementation of EfS in universities. As we have outlined there are many aspects to the development of EfS curriculum. It is like a jig-saw puzzle, representing the complexity of relationships associated with curriculum change. To achieve EfS we may not need to have all the pieces of the jig-saw fitting perfectly, but we will need most of the pieces in place before EfS will be embedded.

Does this mean Ockham's Razor is irrelevant? Is it impossible to assemble our "EfS jig-saw"? We suggest that it is a difficult but not impossible task. The complexity of our task is clear. Yet we suggest that our task is manageable if we use a systemic approach to recognize the range of elements that make up the EfS picture, and how they relate to one another. Figure 3 presents such a relationship, drawing on the elements we have discussed, including an expansion of some. It preferences the

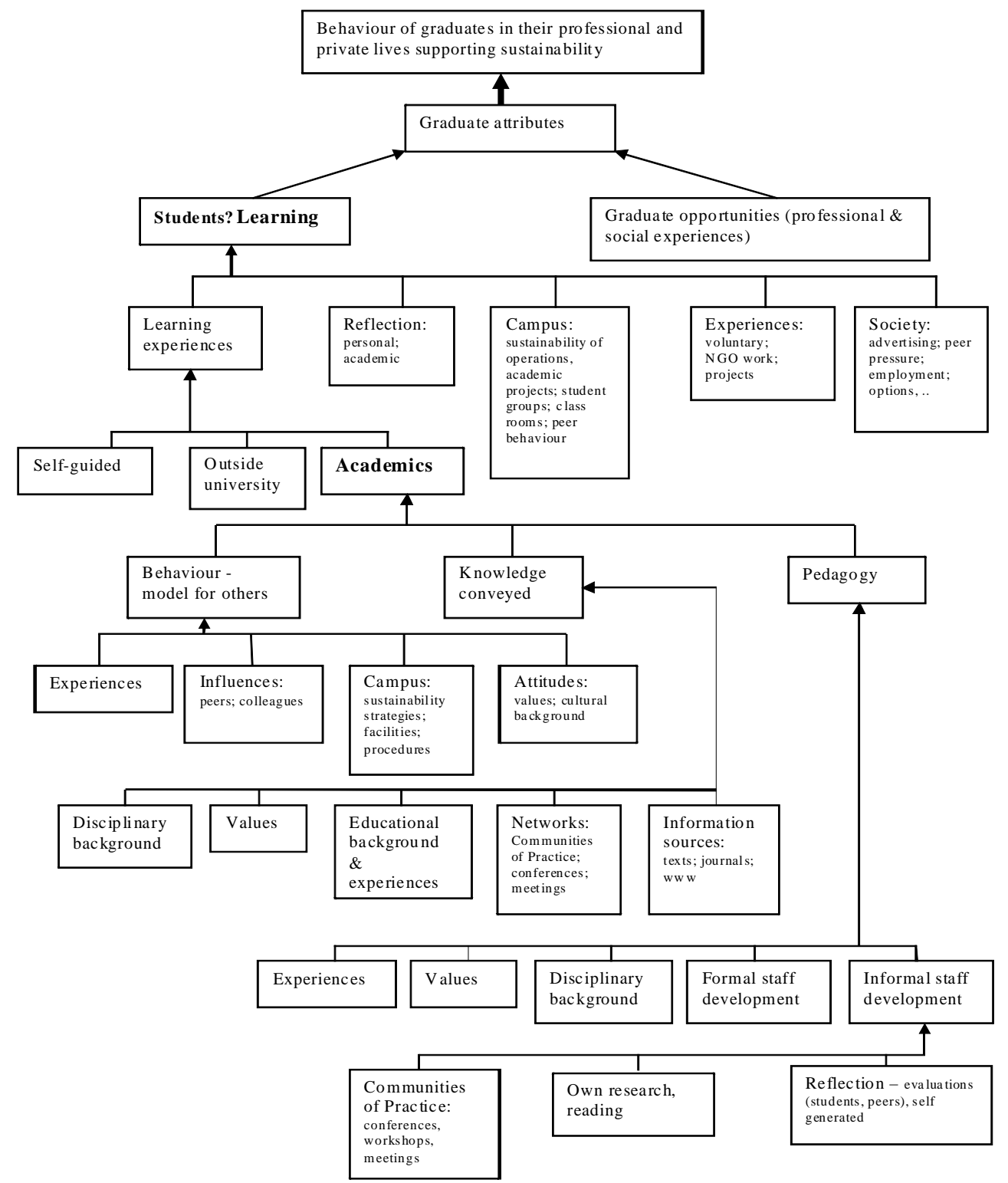

Figure 3.

Overview of the elements of the Education for Sustainability Jig-Saw.

${ }^{2}$ The concept of Ockham's Razor is used in the sciences. It has many interpretations such as: when you have two competing theories that make exactly the same predictions, the simpler one is the better; and sometimes that the simplest solution is usually the correct one. Broadly the approach is to cut through to the simple solution or approach. 
role of academics-since including the complexity of university strategies is beyond a simple diagram. It highlights the purpose of EfS-being to educate graduates enabling them to take action to achieve sustainability.

As with any interpretation of social phenomena this representation of the EfS jig-saw is dependent on our understanding of the situation and its supporting data. Others will have slightly different interpretations. By illustrating our interpretation we hope that we will facilitate discussion amongst EfS researchers, not so much about the precise details of the jig-saw (Figure 3) but of its broad components and how we can work creatively with them to bring about change in universities. Fortunately university staff involved with EfS are in a good position to show this creativity, because, as Gardner (2006: pp. 80-81) notes, creativity emerges from the interaction of: an individual (who has mastered some discipline or domain of practice); their cultural domain (in which the individual is working); and their social field that provides "access to relevant educational experiences as well as opportunities to perform”.

In this article we have briefly outlined the key elements and connections that we, and other researchers, have been working on to guide curriculum change. However, the critical aspect of $\mathrm{EfS}$, and where ockham's razor helps us, is to recognize the role that the values of disciplines, and the academics themselves, play in influencing change. Value based choices will be involved in working with all the elements we have discussed: organizational change; academic development; curriculum development and pedagogy; campus as a learning laboratory; graduate attributes; and the role of professional/accrediting bodies.

Implementation of EfS will require the creative adoption of the knowledge and experiences we have discussed above, and the creative adaption of this understanding to specific situations. Within this context we can all contribute to the implementation of EfS if we recognize the issues discussed in this paper, and tailor our responses to the situations of the university (and disciplines) we have targeted.

\section{Acknowledgements}

Our sincere appreciation goes to all those at RMIT who have helped with research supported by an Australian Research Council grant and its associated Community of Practice, plus colleagues at other universities whose research and discussions have helped contribute to the literature and thinking around EfS, especially leading EfS researchers like Prof John Fien.

\section{REFERENCES}

Association for the Advancement of Sustainability in Higher Education (2010). Curriculum. URL (last checked June 2010). http://www.aashe.org/resources/curriculum.php

Australian Institute of Management (2008). Code of conduct-Guides to good management practice. URL (last checked January 2010). http://www.aim.com.au/about/conduct.html

Babylon Ltd. (2009). Definition of professional associations. URL (last checked January 2010).

http://dictionary.babylon.com/professional\%20associations

Barnett, R. (1997). Higher education: A critical business. Buckingham: Open University Press.

Beringer, A. (2006). Campus sustainability audit research in Atlantic Canada: Pioneering the campus sustainability assessment framework. International Journal of Sustainability in Higher Education, 7, 437455. doi:10.1108/14676370610702235
Bowden, J., \& Masters, G. N. (1993). Implications for higher education of a competency-based approach to education and training. Canberra, ACT: Australian Government Publishing Service.

Boyer, E. (1990). Scholarship Reconsidered: Priorities for the Professoriate. Princeton, NJ: Carnegie Foundation for the Advancement of Teaching, University of Princeton.

Brunetti, A. J., Royann, J. P., \& Sawada, B. (2003). Team projectbased leaning enhances awareness of sustainability at the University of British Columbia, Canada. International Journal of Sustainability in Higher Education, 4, 210-217. doi:10.1108/14676370310485401

Carr-Saunders, A. M., \& Wilson, P. A. (1968). The professions. London: Frank Cass and Co.

Creighton, S. H. (1998) Greening the Ivory Tower: Improving the environmental track record of universities, colleges, and other institutions. Cambridge, MA: MIT Press.

Corneya, G., \& Reid, A. (2007). Student teachers' learning about subject matter and pedagogy in education for sustainable development. Environmental Education Research, 13, 33-54. doi:10.1080/13504620601122632

Cotton, D. R. E., Warren, M. F., Maiboroda, O., \& Bailey, I. (2007). Sustainable development, higher education and pedagogy: A study of lecturers' beliefs and attitudes. Environmental Education Research, 13, 579-597. doi:10.1080/13504620701659061

Dawe, G., Jucker, R., \& Martin, S. (2005). Sustainability literacy in higher education: Current practice and future developments. London: The Higher Education Academy, U.K.

De la Harpe, B., \& Thomas, I. (2009). Curriculum change in universities: Conditions that facilitate education for sustainable development. Journal of Education for Sustainable Development, 3, 75-85. doi:10.1177/097340820900300115

Department of the Environment, Water, Heritage and the Arts (2009). Living Sustainably: The Australian Government's National Action Plan for Education for Sustainability. Canberra, ACT: Australian Government Department of the Environment, Water, Heritage and the Arts.

Department of Innovation, Industry and Regional Development (2010). Jobs for the Future Economy: Victoria's Action Plan for Green Jobs. Melbourne, VIC: Department of Innovation, Industry and Regional Development.

Dzinkowski, R. (2007). Saving the environment. Strategic Finance, 89, 50-54.

Eckel, P. D. (2002). Assessing change and transformation in higher education: An essential task for leaders. Metropolitan Universities: An International Forum, 13, 81-93.

Eckel, P. D., Green, M., Hill, B., \& Mallon, W. (1999). Taking charge of change: A primer for colleges and universities. Washington DC: American Council on Education.

Engineers Australia (2006). Engineers Australia policy on accreditation of professional engineering programs. URL (last checked July 2009). http://www.engineersaustralia.org.au/

Fien, J. (2001). Education for sustainability: Reorientating Australian schools for a sustainable future. Melbourne, VIC: Australian Conservation Foundation.

Filho, W. L. (2000). Dealing with misconceptions on the concept of sustainability. International Journal of Sustainability in Higher Education, 1, 9-19. doi:10.1108/1467630010307066

Ford, M. (2002). Beyond the modern university: Towards a constructive post-modern university. Westport, CT: Praeger.

Gardner, H. (2006) Minds viewed globally: A personal introduction. In H. Gardner (Ed.), Five minds for the future (pp. 1-19). Boston, MA: Harvard Business School Press.

Gibbs, G. (1995). Changing teachers' conceptions of teaching and learning through action research. In A. Brew (Ed.), Directions in staff development (pp. 21-35). Buckingham: Society for Research into Higher Education and Open University Press.

Gonczi, A. (1994). Competency based assessment in the professions in Australia. Assessment in Education: Principles, Policy and Practice, 1, 27-44. doi:10.1080/0969594940010103

Hegarty, K. (2008). Shaping the self to sustain the other: Mapping impacts of academic identity in education for sustainability. Environmental Education Research, 14, 681-692. 
doi: $10.1080 / 13504620802464858$

Higher Education Academy (2006) Sustainable development in higher education: Current practice and future developments: A progress report for senior managers in higher education. URL (last checked March 2006). http://www.heacademy.ac.uk/4074.htm

Higher Education Funding Council for England (HEFCE) (2009). Sustainable development in higher education 2008 update to strategic statement and action plan. London: Higher Education Funding Council for England.

Holdsworth, S., Bekessy, S., Hayles, C., Mnguni, P., \& Thomas, I. (2006a). Beyond leather patches project for sustainability education at RMIT. In W. L. Filho, \& D. Carpenter (Eds.), University sustainability in the Australasian university context (pp. 107-128). Frankfurt: Peter Lang Scientific Publishers.

Holdsworth, S., Bekessy, S., Hayles, C., Mnguni, P., \& Thomas, I. (2006b). Beyond leather patches: Sustainability education at RMIT University, Australia. In W. L. Filho (Ed.), Innovation, education and communication for sustainable development (pp. 153-176). Frankfurt: Peter Lang Scientific Publishers.

Holdsworth, S., Wyborn, C., Bekessy, S., \& Thomas, I. (2008). Professional development for education for sustainability: How advanced are Australian universities? International Journal of Sustainability in Higher Education, 9, 131-146. doi:10.1108/14676370810856288

Holdsworth, S., Bekessy, S., \& Thomas, I. (2009). Evaluation of curriculum change at RMIT: Experiences of the BELP project. Reflecting Education, 5, 51-72.

Huckle, J. (2005). Education for sustainable development: A briefing paper for the Teacher Training Agency. URL (last checked 1 February 2009).

www.ttrb.ac.uk/viewArticle2.aspx?contentId=11324

Jones, P., Trier, C. J., \& Richards, J. P. (2009). Embedding education for sustainable development in higher education: A case study examining common challenges and opportunities for undergraduate programmes. International Journal of Educational Research, 47, 2-10.

Kolb, D. (1976). Learning style inventory: Technical manual. Boston, MA: McBar.

Kemmis, S., \& Smith, T. J. (2008). Enabling praxis: Challenges for education. Rotterdam: Sense Publishers.

Khaleeli, R. (2006). Engineering. URL (last checked August 2006). http://www.bth.se/ste/tmslm.nsf/pages/821a557770b7f60ac12571810 028acf5!OpenDocument

Kreber, C. (1999). A course-based approach to the development of teaching-scholarship: A case study, Teaching in Higher Education, 4, 309-325. doi:10.1080/1356251990040301

Lang, J., Thomas, I., \& Wilson, A. (2006). Education for sustainability in Australian universities: Where is the action? Australian Journal of Environmental Education, 22, 45-58.

Lederer, J., \& Seasons, M. (2005). Understanding the university-community alliance: The Waterloo experience. Canadian Journal of Urban Research, 14, 237-261.

Marinova, D., \& McGrath, N. (2004). A transdisciplinary approach to teaching and learning sustainability: A pedagogy for life. In Seeking educational excellence, proceedings of the 13th annual Teaching and Learning Forum. Murdoch, WA: Murdoch University,

M'Gonigle, M., \& Starke, J. (2006). Planet U: Sustaining the world, reinventing the university. Gabriola Island, BC: New Society Publishers.

McGinty, S., \& McTaggart, R. (2000). Changing university teaching and curriculum: Points of reference for university teachers. Annual Conference of the Australian Association for Research in Education, Sydney, 4-7 December.

Macquarie University (1981). The Macquarie Dictionary. McMahons Point, NSW: Macquarie Library.

Morris, J. P. (2005) The hidden economics of campus sustainability.
Facilities Manager, 21, 24-26.

Noonan, D., \& Thomas, I. (2004). Greening universities in Australia: Progress and possibilities. Australian Journal of Environmental Education, 20, 67-80.

Oblinger, D. G. (2009) Sustainability. Review, 44, 112.

Parker, J., Wade, R., \& Van Winsum, A. (2004). Citizenship, and community from local to global: Implications for higher education of a global citizenship approach. In J. Blewitt, \& C. Cullingford (Eds.), The sustainability curriculum: The challenge for higher education (pp. 63-77). London: Earthscan.

Parkin, S., Johnston, A., Buckland, H., Brookes, F., \& White, E. (2004). Learning and skills for sustainable development: Developing a sustainability literate society-Guidance for higher education institutions, London: Forum for the Future.

Pitman, T., \& Broomhall, S. (2009). Australian universities, generic skills and lifelong learning. International Journal of Lifelong Education, 28, 439-458. doi:10.1080/02601370903031280

RMIT (2012). About RMIT. URL (last checked July 2012). http://www.rmit.edu.au/about

Robinson, K. (2001) Out of our minds: Learning to be creative. West Sussex: Capstone Publishing.

Rowland, S. (2003). Academic development: A practical or theoretical business? In H. Eggins, \& R. Macdonald (Eds.), The scholarship of academic development (pp. 13-22). Buckingham: Society for Research into Higher Education and Open University Press.

Savan, B. (2004). Community-university partnerships: Linking research and action for sustainable community development. Community Development Journal, 39, 372-384. doi:10.1093/cdj/bsh033

Sherren, K. (2007). Is there a sustainability canon? An exploration and aggregation of expert opinions. Environmentalist, 27, 341-347. doi:10.1007/s10669-007-9046-3

Sterling, S. (2001). Sustainable education: Re-visioning learning and change. Bristol: Schumacher Briefings.

Sterling, S., \& Thomas, I. (2006). Education for sustainability: The role of capabilities in guiding university curricula. International Journal of Innovation and Sustainable Development, 1, 349-370. doi:10.1504/IJISD.2006.013735

Sustainable Campus Group (2009). Victorian sustainable campus group report for 2008. URL (last checked June 2009). http://www.monash.edu/research/sustainability-institute/assets/docu ments/1_victorian_scg_report_for_2008_final.pdf

Thomas, I. G. (2004). Sustainability in tertiary curricula: What is stopping it happening? International Journal of Sustainability in Higher Education, 5, 33-47. doi:10.1108/14676370410517387

Thomas, I. G., \& Nicita, J. (2002). Sustainability education and Australian universities. Environmental Education Research, 8, 475-492. doi:10.1080/1350462022000026845

Thomas, I., Hegarty, K, Whitman, S., \& MacGregor, V. (2012). Professional associations: Their role in promoting sustainable development. Journal of Education for Sustainable Development, 6, 123-138. doi:10.1177/097340821100600119

Tilbury, D., Keogh, A., Leighton, A., \& Kent, J. (2005). A national review of environmental education and its contribution to sustainability in Australia: Further and higher education. http://www.aries.mq.edu.au/project.htm

Trigwell, K. (1995). Increasing faculty understanding of teaching. In W. A. Wright (Ed.), Teaching improvement practices: Successful faculty development strategies (pp. 76-100). Boston, MA: Anker.

University Leaders for a Sustainable Future (2006). Home Page. URL (last checked September 2006). http://www.ulsf.org

Wells, C. W., Savanick, S., \& Manning, C. (2009). Using a class to conduct a carbon inventory: A case study with practical results at Macalester College. International Journal of Sustainability in Higher Education, 10, 228-238. doi:10.1108/14676370910972549 